\title{
An Examination of Differences between the Mean Indicator Ratings by Different Stakeholders in Distance Education Programme
}

\author{
Ernest Adu-Gyamfi ${ }^{1}$, Paul Kwadwo Addo ${ }^{2}$ (EdD) \& Charles Asamoah-Boateng ${ }^{3}$ \\ ${ }^{1}$ Registrar's Office, Kwame Nkrumah University of Science and Technology, Kumasi, Ghana \\ ${ }^{2}$ Faculty of Educational Studies, Kwame Nkrumah University of Science and Technology, Kumasi, Ghana \\ ${ }^{3}$ Faculty of Social Sciences, Kwame Nkrumah University of Science and Technology, Kumasi, Ghana \\ Correspondence: Dr. Paul Kwadwo Addo, Kwame Nkrumah University of Science and Technology, Faculty of \\ Educational Studies, University Post Office. Private Mail Bag. Kumasi. Ghana. E-mail: pkaddo@yahoo.com
}

\author{
Received: May 17, 2019 \\ Accepted: June 28, 2019 \\ Online Published: July 2, 2019 \\ doi:10.5430/ijhe.v8n4p72 \\ URL: https://doi.org/10.5430/ijhe.v8n4p72
}

\begin{abstract}
The continued rapid growth of distance education programmes in higher education has brought concerns regarding how stakeholers perceive quality in distance education. The study examined the differences between the mean indicator ratings by different stakeholders in a distance learning programme. The study adopted a case study research design to collect data from 320 students, 56 facilitators and 24 administrative staff selected randomly from the Institute of Distance Learning, Kwame Nkrumah University of Science and Technology in Ghana. The data collected through questionnaires were analysed using the statistical package for the social sciences (SPSS) software, version 20. Mean indicator rating analysis revealed that students' highest perception of quality was on support services and the lowest was academic integrity and institutional prestige. Whilst both facilitators and administrators rated support services as the highest, infrastructure scored the lowest. The results of the study therefore, revealed common benchmarks and quality indicator (support services) that all parties deem important in designing, implementing, and evaluating distance education programmes. Respondents noted the lack of appropriate tools and media; unavailability of reliable technology and technological plan; ineffective communication and co-ordination; and, time constraints as some of the quality challenges for distance education at the Institute. The study recommends monitoring and evaluation of service delivery for distance learning programmes to ensure fitness for purpose, value for money and customer satisfaction.
\end{abstract}

Keywords: distance education, mean indicator ratings, service delivery, perception, academic integrity, institutional prestige

\section{Introduction}

Many distance education institutions have adopted policies and mechanisms geared towards the assurance of quality in the delivery of education. Although the contextual element for institutional quality assurance remains an issue, attempts to provide a generally acceptable set of standards for measuring quality is still unclear (Tsinidou, Gerogiannis and Fitsilis, 2010). The diverse users of distance higher education come with various perceptions that tend to influence their attitude towards the acceptance and use of distance education. In view of the above, examining their perceptions and expectations becomes critical for meeting institutional objectives. Parker (2008) observed that in trying to define the quality of any product or service, quality must be seen as a relative experience realised mostly through an individual's level of experience. Distance education quality assurance systems should, thus, offer opportunities for assessing the views and perceptions of the people who are involved (Lerra, 2014). Thus, moving into the future, quality assurance policies and practices for distance education programmes must incorporate the perceptions of the various user groups, well-structured and effective quality mechanism that have the potency to improve institutional performance and customer satisfaction.

The Institute of Distance Learning (IDL) of Kwame Nkrumah University of Science and Technology (KNUST) in Ghana after its establishment in 2005 has a strategic goal of expanding access to continuing and higher education and training through the distance mode (IDL PIAN2K17, 2013). It has, therefore, introduced comprehensive management strategies as well as quality assurance systems, geared towards the realisation of its vision and mission. With the aim of expanding access to higher education and ultimately ensuring customer satisfaction and sustainability, the major 
question that arises is whether users of distance education obtain satisfaction. Even though a number of research have been conducted on several aspects of distance learning at the Institute (Tracer Study Report, 2014), there is no research that addresses the perceptions of diverse users of distance learning and how they perceive quality at the Institute.

The questions that this study seeks to answer are:

i. What is stakeholders' perception of the quality of education at IDL, KNUST?; and

ii. What challenges affect quality education at IDL?

\section{Methodology}

\subsection{Study Method}

A quantitative, non-experimental research approach was employed to examine the difference between the mean indicator ratings by different stakeholders. KNUST-IDL in Ghana was selected as a case. In this study, the use of the case study design was necessitated by the need to undertake a detailed empirical examination of how the different stakeholders perceive the quality of distance education at IDL-KNUST. Within the specific concept of quality of education at IDL-KNUST, concentrating on the Institute (IDL-KNUST) and the specific stakeholders (learners, facilitators and administrators) offers the most reliable and simple way to examine the perception of quality education at its most basic level.

\subsection{Population and Sample Size}

The target population of the study includes all students, facilitators/instructors and administrators of distance education programmes at IDL-KNUST. Based on the target population of the study, a sample size of 400 individuals consisting of 320 students, 24 administrative staff and 56 facilitator/instructors were considered. The determination of the sample sizes was done using the sample size determination table developed by Krejcie and Morgan (1970). The stratified random sampling method was used to select the various participants.

\subsection{Data Source}

Both primary and secondary data were collected for the study. The primary data included socio-economic data of respondents, data on respondents' perception concerning support services, institutional credibility, academic integrity, infrastructure, cost effectiveness, reward and motivation, and other information relating to stakeholder perceived quality of distance education at the institute. The primary data were obtained through field survey. Secondary data complementing the above were collected from review of key documents on quality assurance at IDL-KNUST. Three sets of questionnaires were designed and administered to obtain data. To ensure reliability, the questionnaires used in the study were pre-tested on individuals with similar characteristics as the sample, with the view to identifying any error, inconsistency and ambiguity, so as to get them corrected before the final administration. For the Likert scale constructs, data from the pre-testing were used to test the reliability and internal consistency of the Likert Scale items used by calculating the Cronbach's Alpha coefficients using the Statistical Parkage for Social Sciences (SPSS version 20).

\subsection{Data Analysis}

Data collected for the study were analysed using the Statistical Parkage for Social Sciences (IBM version 20) and Microsoft Excel (2010 version). Inferential statistics used in the analysis included factor analysis and independent sample t-test. The multilevel confirmatory factor analysis (MCFA) was performed to identify the principal components or dimensions of (distance education (DE)) quality at KNUST-IDL. Independent sample t-test was employed to determine the significance of difference between mean indicator ratings of the different stakeholders on the different components of DE quality at KNUST-IDL.

\section{Results and Discussion}

\subsection{Stakeholders Mean Indicators on the Perception of DE Quality at KNUST-IDL}

The study examined the mean indicator ratings of the various dimensions of DE quality as perceived by stakeholders (students, instructors/facilitators and administrators). From the results (Table 1), it is noted that the different stakeholders' perception about the quality of DE at KNUST-IDL vary. For students, support services recorded the highest mean rating $(3.4 \pm 0.944)$ while academic integrity and institutional prestige was rated the least $(2.0 \pm 0.669)$. In other words, eventhough for student, suport services was rated higher than academic integrity and institutional prestige, the reponses did no deviate much from the mean in both instances; the responses were concentarted around the mean indicator ratings. On the part of facilitators, Support Services was again rated the highest $(3.0 \pm 0.77)$ while 
Infrastructure was rated the least (2.3 \pm 0.616$)$. Administrators also rated support services as the highest $(2.7 \pm 0.765)$ whiles infrastructure was again rated as the least $(1.7 \pm 0.361)$. The three stakeholders have high mean quality rating on support services relative to the other dimensions and in all situation, individual responses, on the average, were less than one(1) point away from the mean. According to Filippakou (2011), different stakeholders have different perception of DE quality. Stakeholders with low expectation about distance education quality are more likely to rate distance education programmes or institutions higher than those with high expectations. The variation in the mean indicator ratings on the different dimensions of DE quality at KNUST-IDL can, therefore, be attributed to the different levels of understanding, interest and expectations that the different stakeholders have regarding distance education.

Table 1. Stakeholders Perception of IDL on Educational Quality Dimensions

\begin{tabular}{|c|c|c|c|c|c|c|c|c|c|}
\hline \multirow[t]{2}{*}{ Quality Indicators } & \multicolumn{3}{|c|}{ Students } & \multicolumn{3}{|c|}{ Facilitators } & \multicolumn{3}{|c|}{ Administrators } \\
\hline & $\mathrm{N}$ & Mean & SD & $\mathrm{N}$ & Mean & SD & $\mathrm{N}$ & Mean & SD \\
\hline Support Services & 147 & 3.4 & 0.944 & 27 & 3.0 & 0.770 & 20 & 2.7 & 0.765 \\
\hline $\begin{array}{l}\text { Academic Integrity and } \\
\text { Institutional Prestige }\end{array}$ & 147 & 2.0 & 0.669 & 27 & 2.5 & 0.520 & 20 & 1.9 & 0.509 \\
\hline $\begin{array}{l}\text { Cost Effectiveness and Access to } \\
\text { Services }\end{array}$ & 147 & 3.3 & 0.972 & - & - & - & 20 & 2.6 & 0.391 \\
\hline Infrastructure & 147 & 2.4 & 0.830 & 27 & 2.3 & 0.616 & 20 & 1.7 & 0.361 \\
\hline Reward and Motivation & - & - & - & 27 & 2.8 & 0.756 & 20 & 2.4 & 0.447 \\
\hline
\end{tabular}

Source: Field Survey (2016)

\subsection{Comparison of Different Stakeholder Perception for Quality at IDL-KNUST}

The mean ratings of stakeholders on the various indicators measuring DE quality at KNUST-IDL were compared and the results were as follows:

\subsubsection{Student versus Administrators}

To find out whether there was significant difference between the mean ratings of DE quality at KNUST-IDL by Students and Administrators, an independent sample t-test was used. The independent-sample t-test was conducted to compare mean ratings of distance education quality by Students and Administrators. The results, as presented in Table 2 show that there was a significant difference between the mean ratings of indicators on Support Services $(\mathrm{t}(165)=-3.316, \mathrm{p}=0.00)$, Cost Effectiveness $(\mathrm{t}(165)=-3.468, \mathrm{p}=0.001)$ and Infrastructure $(\mathrm{t}(165)=-4.046, \mathrm{p}=0.00)$. There is, however, no significant difference for mean ratings on Academic Integrity and Institutional Prestige $(\mathrm{t}(165)=-0.864, \mathrm{p}=0.395)$. Inferring from the results above, Students and Administrators have different perceptions for distance education quality at KNUST-IDL; specifically, with regards to user Support Services, Cost Effectiveness and Infrastructure.

Differences in perceptions of quality between Students and Administrators of DE programmes can be supported by theories and findings from many empirical studies. Abidin (2015) noted that there is often differences in perceptions between internal stakeholders (Facilitators and Administrators) and external stakeholders (Students) of DE. Abidin (2015) observed that internal stakeholders are likely to perceive the quality of DE high compared to external stakeholders. From the result of this study, a measure of the perceived quality gap between internal stakeholders (Administrators) and external stakeholders (Students) revealed that the external stakeholders (students) rather had the highest mean quality perception rating than the internal stakeholders. This is in sharp contrast to the findings of Abidin (2015). One reason that could account for this observation is that by virtue of the opportunity to learn and work at the same time provided by DE, students turn to overlook critical issues about quality and this might have accounted for the high rating of the quality of DE at KNUST-IDL by Students relative to Administrators. This position is consistent with Moore's (2013) observation that students are sometimes quite grateful and content with the opportunities offered by DE and therefore are less critical about quality demands. 
Table 2. Comparing Mean Quality Indicator Ratings for Students and Administrators

\begin{tabular}{|c|c|c|c|c|c|c|c|}
\hline \multirow{3}{*}{ Quality dimensions } & \multicolumn{4}{|c|}{ Stakeholders } & \multirow{2}{*}{\multicolumn{3}{|c|}{$\begin{array}{l}\text { Test of equality of means } \\
\mathrm{df}=165\end{array}$}} \\
\hline & Studer & & Admi & trators & & & \\
\hline & Mean & SD & Mean & SD & Mean difference & $\mathrm{t}$ & P-value \\
\hline Support Services & 3.4 & 0.944 & 2.7 & 0.765 & -0.623 & -3.316 & 0.003 \\
\hline Academic integrity & 2.0 & 0,669 & 1.9 & 0.509 & -0.109 & -0.864 & 0.395 \\
\hline Cost effectiveness & 3.3 & 0.972 & 2.6 & 0.391 & -0.764 & -3.468 & 0.001 \\
\hline Infrastructure & 2.4 & 0.830 & 1.7 & 0.361 & -0.762 & -4.046 & 0.000 \\
\hline
\end{tabular}

Source: Field Survey

\subsubsection{Students versus Facilitators}

Difference in perception of quality for DE at KNUST-IDL was examined using an independent sample t-test. Results of the analysis are presented in Table 3. The independent-sample t-test was conducted to compare mean ratings of DE quality by students and facilitators. The results as presented in Table 3 show that there is a significant difference between the mean rating of indicators on support services $(t(172)=-2.241, P=0.030)$ and academic integrity and institutional prestige $(\mathrm{t}(172)=4.419, \mathrm{p}=.000)$ but not the same with infrastructure $(\mathrm{t}(172)=-0.875$, $\mathrm{p}=0.386$ ). Difference in the perception of quality of DE by facilitators/teachers and students have been reported by several studies including that of Buntat et al. (2013), Abidin (2015), Bukaliya and Kudakwashe (2015). In all these studies, it had been observed that facilitators tend to have higher perception of quality of DE compared to students. Quite interestingly, the findings of this study have revealed that while facilitators had high perception for quality in terms of academic integrity and institutional prestige, students' perception was low. The perception of students on support services as a quality dimension was, however higher than facilitators. This observation reveals that perception on quality of DE is not only reflected by whether the respondent is an internal or external stakeholder of DE but also dependent on the dimension of DE under consideration.

Table 3. Comparing Mean Quality Indicator Ratings for Facilitators and Students

\begin{tabular}{lllllllll}
\hline & \multicolumn{2}{l}{$\begin{array}{l}\text { Stakeholders } \\
\text { Facilitator }\end{array}$} & \multicolumn{2}{l}{ Student } & \multicolumn{2}{l}{$\begin{array}{l}\text { Test of equality of means } \\
\text { df=172 }\end{array}$} \\
\hline Quality dimensions & Mean & SD & Mean & SD & $\begin{array}{l}\text { Mean } \\
\text { difference }\end{array}$ & T & P-value \\
\hline Support Services & 3.0 & 0.770 & 3.4 & 0.944 & -.37960 & -2.241 & 0.030 \\
Academic Integrity and institutional prestige & 2.5 & 0.520 & 2.0 & 0,669 & .49598 & 4.419 & .000 \\
Infrastructure & & & & & & & \\
\hline
\end{tabular}

Source: Field Survey

\subsubsection{Administrators versus Facilitators}

An independent-sample t-test was also conducted to compare mean ratings of DE quality by administrators and facilitators. The results obtained are as presented in Table 4. From the results, it is shown that a significant difference exists between the mean ratings of DE quality at KNUST-IDL as perceived by administrators and facilitators on academic integrity and institutional prestige $(\mathrm{t}(45)=-4.021, \mathrm{p}=0.00)$, infrastructure and learning environment $(\mathrm{t}(45)=$ -2.128, $\mathrm{p}=0.04$ ) and Reward and Motivation $(\mathrm{t}(45)=-2.29, \mathrm{p}=0.03)$. With regards to support services, the difference were not statistically significant $(\mathrm{t}(45)=-1.069, \mathrm{p}=0.291)$. This result has demonstrated that, beyond what Abidin (2015) noted, difference in perception of quality exists even within internal stakeholders. The result on the difference in perception of DE quality by administrators and facilitators can be explained in various perspectives. In the first instance, although both the facilitators and administrators are internal stakeholders, the roles they play differ. The difference in roles affect each stakeholder's knowledge and view on quality. In areas where limited collaboration exist, different stakeholders may have near no knowledge at all on other components of DE quality and therefore, may result in divergent views regarding quality on some dimensions. Bukaliya and Kudakwashe (2015) alluded to a similar perspective when they indicated that lack of knowledge on DE activities bring about different perception of quality on DE. 
Table 4. Comparing Mean Quality Indicator Rating for Facilitators and Administrators

\begin{tabular}{|c|c|c|c|c|c|c|c|c|}
\hline \multirow[b]{2}{*}{ Quality Dimensions } & & \multicolumn{4}{|c|}{ Stakeholders } & \multicolumn{3}{|c|}{$\begin{array}{l}\text { Test of equality of means } \\
\mathrm{df}=165\end{array}$} \\
\hline & & Mean & SD & Mean & SD & $\begin{array}{l}\text { Mean } \\
\text { difference }\end{array}$ & $\mathrm{T}$ & P-value \\
\hline Support Services & & 2.7 & 0.765 & 3.0 & 0.770 & -.24340 & -1.069 & .291 \\
\hline $\begin{array}{l}\text { Academic Integrity and } \\
\text { Prestige }\end{array}$ & Institutional & 1.9 & 0.509 & 2.5 & 0.520 & -0.605 & -4.021 & 0.00 \\
\hline Infrastructure & & 1.7 & 0.361 & 2.3 & 0.616 & -0.408 & -2.128 & 0.04 \\
\hline Reward and Motivation & & 2.4 & 0.447 & 2.8 & 0.756 & -0.408 & -2.29 & 0.03 \\
\hline
\end{tabular}

Source: Field Survey

\subsection{Challenges that Affect Quality Assurance Practices at IDL}

The challenges that affect quality practices were identified from responses of Students, Facilitators and Administrative Staff at KNUST-IDL as presented in Table 5.

The results from the analysis of data collected show that about $42 \%, 89 \%$ and $70 \%$ of students, facilitators and administrative staff respectively noted that there is limited availability of appropriate tools and media, which affects quality of DE. The specific tools and media mentioned included classroom teaching aids such as projectors and laptop computers. These were identified as inadequate at the KNUST-IDL. Some students also stated that the virtual classroom which was meant to provide access to online information avenue and discussion platforms was not accessible to all students; and, even those who are able to access the facility indicated that very limited information were shared on the platform. This has a high tendency to affect the quality of course delivery at the IDL.

Majority of the students, facilitators and administrative staff interviewed indicated that there is lack of effective communication and co-ordination at the Institute $(84 \%, 79 \%$ and $90 \%)$. They also lamented on the institute's commitment to quality evaluation and assessment practices which go a long way to affect the quality of DE delivery (85\%, 50\% and $60 \%$ respectively).

Moreover, while students did not mention institutional support as a challenging factor, majority (64\%) of the facilitators and about half $(40 \%)$ of the administrative staff mentioned institutional support and resources as a challenging factor. In addition, while no student mentioned issues of technological plan, majority of both the facilitators and administrative staff stated that the absence of a well-structured technological plan affects the quality of DE delivery. Among the factors mentioned by the highest number (87\%) of students as affecting quality in DE at IDL-KNUST is the issue of time constraints. Most students lamented that the time frame within which their courses were structured was too short to enable them acquire the necessary knowledge and skills. In addition, students attributed the limited academic contact hours to the issue of time constraint and added that it becomes an impediment for quality distance education delivery. The results also indicated that adherence to quality standards was noted by majority of both the facilitators and administrative staff ( $71 \%$ and $75 \%$ respectively) as an important factor that affect quality of DE at the institute. The availability of reliable technology was also mentioned by $79 \%$ of Students, $14 \%$ of facilitators and $60 \%$ of administrative staff as a challenging factor for quality assurance at the institute. 
Table 5. Challenges and Factors That Affects Quality Assurance Practices the IDL

\begin{tabular}{|c|c|c|c|c|c|c|c|}
\hline \multirow[b]{2}{*}{ Challenges/factors that affect quality } & \multicolumn{2}{|c|}{$\begin{array}{l}\text { Students } \\
(N=147)\end{array}$} & \multicolumn{2}{|c|}{$\begin{array}{l}\text { Facilitators } \\
(N=28)\end{array}$} & \multicolumn{2}{|c|}{$\begin{array}{l}\text { Administrative } \\
(N=20)\end{array}$} & \multirow[t]{2}{*}{ Staffs } \\
\hline & Freq* & $\%$ & Freq* & $\%$ & Freq* & $\%$ & \\
\hline Appropriate tools and media & 62 & 42 & 25 & 89 & 14 & 70 & \\
\hline Institutional Support/Resources & - & - & 18 & 64 & 8 & 40 & \\
\hline Effective Communication and Coordination & 124 & 84 & 22 & 79 & 18 & 90 & \\
\hline Unavailability/Lack of Technological Plan & - & & 24 & 86 & 15 & 75 & \\
\hline Reliable Technology & 116 & 79 & 4 & 14 & 12 & 60 & \\
\hline $\begin{array}{l}\text { Commitment to Quality Evaluation and } \\
\text { Assessment Practice }\end{array}$ & 125 & 85 & 14 & 50 & 12 & 60 & \\
\hline Adherence to Quality Standards & - & - & 20 & 71 & 15 & 75 & \\
\hline Time constraints & 128 & 87 & 6 & 21 & 14 & 70 & \\
\hline
\end{tabular}

Source: Field Survey Data

*Multiple frequency

\section{Recommendation and Conclusion}

\subsection{Conclusion}

On the basis on the findings obtained in the study, the researchers conclude that quality in distance education is a multi-dimensional concept with different stakeholders. There are also significant differences in stakeholder perceived levels of quality at the Institute, depending on the type of stakeholder being considered. Regardless of the differences in the perceived levels of quality, it is clear among the various stakeholders that quality distance education should have consideration for cost effectiveness and access to services, support services, academic integrity and institutional prestige, infrastructure and learning environment, and reward and motivation as key indicators for distance education quality decisions. Management and governing bodies of distance education institutions should, therefore, rely more on both theoretical and empirical foundations in establishing quality indicators for distance education as a critical concept in higher education delivery.

\subsection{Recommendations}

1. The Virtual Classroom (V-Class) platform which has been established to provide access to online information and discussion platforms for both facilitators and students must be seen to be functional with adequate information. Every information needed to assist students and facilitators must be on the V-Class platform to provide a virtual access to information.

2. Following from the above, it is recommended that the institute must draw up and follow a reliable technology and technological plan so that it can deliver as a true distance learning institution.

3. The various support services currently being implemented by KNUST-IDL must be maintained and if possible even improved upon. This way, students' outcomes can significantly improve.

4. Channels of communication the Institute uses to reach out to current and prospective students could be improved. The V-Class platform could be utilised in this direction.

5. In addition, co-ordination of the various activities of the Institute could be improved so that participants of the Institute's programmes know where to find what and whom to contact on any issue of concern.

6. It is also recommended that the duration of the programmes on offer could be increased as a way to increase the contact hours for students. Alternatively, the number of weekends for face-to-face sessions could be increased so that students' contacts hours could be increased. This is because most Students lamented that the time frame within which their courses were structured was too short to enable them acquire the necessary knowledge and skills.

7. The institute could have a re-look at the appropriateness and adequacy of its infrastructure such as classrooms, tables and chairs, LCD projectors, tools, media, etc. at its various learning centres.

8. It is further recommended that a purposeful periodic monitoring and evaluation of service delivery for IDL-KNUST's programmes could be institutionalised to ensure fitness for purpose, value for money and customer satisfaction. This way, stakeholder concerns would be to improve institutional performance and customer satisfaction. 


\section{References}

Abidin, M. (2015). Higher Education Quality: Perception Differences among Internal and External Stakeholders. International Education Studies, 8(12), 185-192. https://doi.org/10.5539/ies.v8n12p185

Al-Salman, S. M. (2011). Faculty in online learning programs: Competencies and barriers to success. Journal of Applied Learning Technology, 1, 6-13.

Bukaliya, R., \& Kudakwashe, M. (2015). Transforming Stakeholders Perceptions of Open and Distance Learning Through Student Community Service Programmes. International Journal, 100.

Bunglowala, A., \& Asthana, N. (2016). A Total Quality Management Approach in Teaching and Learning Process. International Journal of Management, 7(5).

Buntat, Y., Jabor, M. K., Saud, M. S., Mansor, S. M. S. S., \& Mustaffa, N. H. (2013). Employability skills element's: difference perspective between teaching staff and employers industrial in Malaysia. Procedia-Social and Behavioral Sciences, 93, 1531-1535. https://doi.org/10.1016/j.sbspro.2013.10.077

Field, A. (2005). Factor analysis using SPSS. Retrieved March, 17, 2009.

Filippakou, O. (2011). The idea of quality in higher education: a conceptual approach. Discourse: Studies in the Cultural Politics of Education, 32, 15-28. https://doi.org/10.1080/01596306.2011.537068

Khan, A., Muttakin, M. B., \& Siddiqui, J. (2013). Corporate governance and corporate social responsibility disclosures: Evidence from an emerging economy. Journal of business ethics, 114(2), 207-223. https://doi.org/10.1007/s10551-012-1336-0

Kotler, P., Ang, S. H., \& Tan, C. T. (1996). Marketing and Management: An Asian Perspective.

Krejcie, R. V., \& Morgan, D. W. (1970). Determining sample size for research activities. Educ psychol meas. https://doi.org/10.1177/001316447003000308

Lenz, T. L., Monaghan, M. S., Wilson, A. F., Tilleman, J. A., Jones, R. M., \& Hayes, M. M. (2006). Using performance-based assessments to evaluate parity between a campus and distance education pathway. American journal of pharmaceutical education, 70(4), 90. https://doi.org/10.5688/aj700490

Lerra, M. D. (2014). The Dynamics and Challenges of Distance Education at Private Higher Institutions in South Ethiopia. Asian Journal Of Humanity, Art And Literature, 1(3), 137-149.

Mbwesa, J. K. (2014). Students' Perceived Quality of Distance Education Courses as a Correlate of Learner Satisfaction: A Case Study of the Bachelor of Education Arts Program, University of Nairobi, Kenya. International Journal of Social Science Studies, 2(2), 86-99. https://doi.org/10.11114/ijsss.v2i2.358

Mills, R., \& Tait, A. (Eds.). (2004). Rethinking learner support in distance education: Change and continuity in an international context. Routledge.

Molefi, F. (2002,). Support services for distance education students at the department of non-formal education. Paper presented at the Distance Education Workshop for Setswana Part-Time Writers, DNFE.

Moore, M. G. (Ed.). (2013). Handbook of distance education. Routledge. https://doi.org/10.4324/9780203803738

Nash, R. D. (2005). Course completion rates among distance learners: Identifying possible methods to improve retention. Online Journal of Distance Learning Administration, 8(4), 1-26.

Parker, N. K. (2008). The quality dilemma in online education revisited. The theory and practice of online learning, 305.

Tsinidou, M., Gerogiannis, V., \& Fitsilis, P. (2010). Evaluation of the factors that determine quality in higher education: an empirical study. Quality Assurance in Education, 18(3), 227-244. https://doi.org/10.1108/09684881011058669

KNUST. (2014). Tracer Study Report. IDL-Kumasi.

Usun, S. (2004). Learner Support Services in Distance Education System (A Case Study of Turkey). Online Submission, 5(4).

Zabadi, A. M. (2013). Implementing total quality management (TQM) on the higher education institutions-A conceptual model. Journal of Finance and Economics, 1(1), 42-60. 